\title{
Biotechnology Education
}

\section{Bioinformatics Training Programs Are Hot but the Labor Market Is Not*}

Received for publication, November 11, 2004

\begin{abstract}
Grant C. Black $§$ and Paula E. Stephanๆ
From the $\ddagger$ School of Business and Economics, Indiana University South Bend, South Bend, Indiana 46634; and |Andrew Young School of Policy Studies, Georgia State University, University Plaza, Atlanta, Georgia 30303-3083
\end{abstract}

\begin{abstract}
Based on a survey of academic training programs and an analysis of advertised job openings, we conclude that the labor market in bioinformatics has changed dramatically from the 1990s to the early 2000s. The number of academic training programs, as well as enrollment in these programs, expanded rapidly during this period. The expansion has created a sizeable pipeline of students who will matriculate from these programs in the near future. Yet, at the same time that this expansion in training programs occurred, demand in the bioinformatics market declined and its origins have shifted largely from industry to academe. Unless conditions in industry change dramatically in the next few years, it is likely that trainees from these programs will have difficulty finding the expected jobs in industry.
\end{abstract}

Keywords: Bioinformatics, computational biology, training program, labor demand, labor supply.

The vast amount of biological data that has become available since the early 1990s has made computational methodologies in the life sciences increasingly important in research. This in turn has created the need for scientists with interdisciplinary skills in computational science and biology and has led to the rapid emergence of bioinformatics as a distinct field.

Little is collectively known about the labor market and training opportunities in bioinformatics, except for the previous work by Stephan and Black [1-3]. In 1998 they analyzed bioinformatics-related position announcements placed in Science as a measure of demand for bioinformatics workers. In 1999 they surveyed all known academic programs related to bioinformatics in the United States to collect information on characteristics of the training programs, starting salaries of recent graduates, and the identity of institutions hiring these graduates.

The information collected by Stephan and Black in these earlier studies is now at least 5 years old. In a field that is fairly stable, data of this age can often present a reasonably reliable indication of current conditions; in an emerging field like bioinformatics, such data give little indication of the market's current condition. For instance, $\sim 50$ more institutions have begun to offer training programs since the 1999 survey. Fueling this expansion, the media has continued to report that the field still offers opportunities and that a shortage of qualified individuals persists [4-7].

\footnotetext{
* This work was supported by a grant from the Alfred P. Sloan Foundation.

$\S$ To whom correspondence should be addressed: School of Business and Economics, Indiana University South Bend, 1700 Mishawaka Ave., South Bend, IN 46634. E-mail: gcblack@ iusb.edu.
}

Moreover, academic programs and articles commonly cite a National Science Foundation estimate that the United States will have 20,000 bioinformatics jobs to fill by the year 2005. ${ }^{1}$ At the same time, the biotechnology industry has faced a considerable economic downturn and restructuring. With such unstable conditions, there has been little accurate information on the changing state of the bioinformatics market over the past 5 years.

To address this dearth of information regarding the bioinformatics labor market, the authors surveyed academic training programs and performed an extensive analysis of recent position announcements [8]. This article summarizes our findings. ${ }^{2}$ All academic programs included in Stephan and Black's original survey as well as all programs identified since the 1999 survey were invited to participate in the new survey designed to collect information on the characteristics of current training programs and the experiences of their recent graduates. The analysis of position announcements included all bioinformatics-related ads placed in Science in 2000 through 2002, as well as recent electronic ads listed on select internet employment boards.

\footnotetext{
${ }^{1}$ The NSF projection is quoted on a number of websites. See, for example, the joint bioinformatics track through the departments of biological sciences and computer science at San Jose State University (www.cs.sjsu.edu/faculty/khuri/Bioinformatics/ description.html), an article in Forbes (March 15, 2001; www. forbes.com/2001/03/15/0315malone.html), and an article in Time (April 29, 2002; www.time.com/time/business/printout/0,8816, 233967,00.html).

2 The full report is available at www.gsu.edu/ ecopes/reports/ Bioinformatics\%20Final\%20Report_Black\%20and\%20Stephan_ June\%202004.pdf.
} 


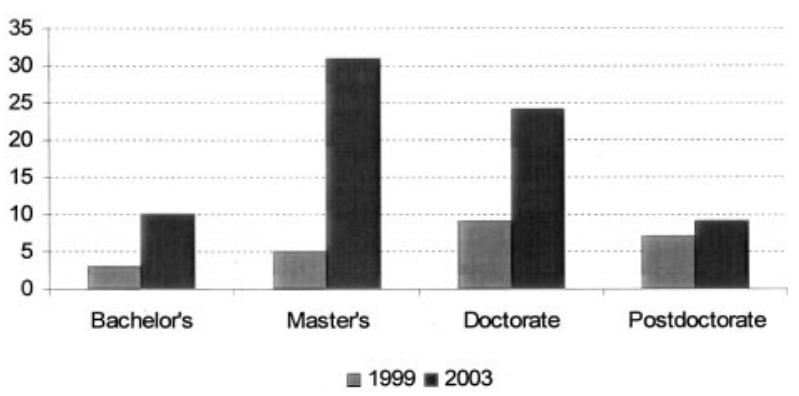

FIG. 1. Number of bioinformatics-related training programs.

\section{BIOINFORMATICS TRAINING}

In March 2003, the 74 academic institutions with known bioinformatics-related training programs at the undergraduate, graduate, and/or postdoctorate level were asked to participate in a web survey. ${ }^{3}$ Forty-four institutions (59.5\%) responded to a part or all of the survey; 30 did not. ${ }^{4}$ Eighteen of the 21 known programs targeted in the 1999 survey replied to the 2003 survey (85.7\% response rate); the response rate was considerably lower for the newer programs with 26 of the 53 replying (49.1\%). One of the 27 nonrespondents in the latter group specifically declined to participate due to the newness of the program; another nonrespondent has a Ph.D. track in genomics and bioinformatics that was only implemented in 2001-2002. We conclude that the survey was reasonably successful at collecting information on established programs in bioinformatics. Data collected from the survey provide less accurate counts regarding newly established programs. This should not affect the accuracy of certain measures, such as graduation counts, because many of the nonresponding programs are too new to have graduated anyone; it does bias downward our counts of the numbers of individuals enrolled in bioinformatics programs.

\section{RAPID GROWTH IN PROGRAMS}

The number of academic training programs related to bioinformatics has grown substantially from the late 1990s to the early 2000s. Fig. 1 shows the number of training programs by degree level, comparing the 1999 data with that for 2003. The highest growth was at the master's level, with over six times as many programs in 2003 as in 1999. This is in part due to the creation since the late 1990s of 12 professional science master's programs in bioinformatics, all initially funded by the Alfred P. Sloan Foundation. The number of doctoral programs grew to 24 in 2003 from nine in 1999. There are still relatively few programs at the bachelor's level, although the number has more than tripled between 1999 and 2003. The small number of postdoctoral training programs undoubtedly reflects in part the informal nature of many postdoctorate training positions.

As seen in Fig. 1, most of the academic programs are relatively new. Of the 10 bachelor's programs, four started

\footnotetext{
${ }^{3}$ Programs were identified from (1) institutions targeted in the 1999 survey, (2) professional science master's programs in bioinformatics sponsored by the Alfred P. Sloan Foundation, (3) extensive internet searches, and (4) talking with individuals involved in established bioinformatics training programs.

${ }^{4}$ The $59.5 \%$ response rate is comparable to that for the 1999 survey of $61.9 \%$.
}

since 2000 and another two began in 1999. Among the master's programs reporting start dates, seven started in 1999 , another seven in 2000, four in 2001, four in 2002, and one in 2003. Seven Ph.D. programs were created in 1999 alone, and seven more have been created since 2000. The reader is reminded that these counts are biased downward given that new programs were less likely to reply than were older programs. Moreover, over one-third of the responding institutions at the time of the survey were considering additional training at different degree levels than currently offered. Unlike the other programs, little growth has occurred at the postdoctorate level since 1999.

\section{EXPANDING ENROLLMENT}

Enrollments in 2002-2003 were much higher than in 1998-1999 due in large part to the rapid growth in the number of programs over the 4-year period. Moreover, given that new programs had a lower response rate than older programs, the reported number of enrollees and the growth rates are biased downward. Undergraduate enrollments in bioinformatics programs increased from $\sim 23$ students in 1999 to 103 in 2003. The number of master's students skyrocketed over this period, going from 30 to over 400. Doctoral enrollments rose substantially as well, increasing from 79 in 1999 to almost 300 in 2003. The number of postdoctorates in bioinformatics programs also increased, rising 88\% from 25 postdoctorates in 1999 to 47 in 2003. While total enrollments across levels of training vary considerably, the average size of a bioinformatics program is similar across the levels. Average enrollment for the 2002-2003 academic year was $\sim 17$ for bachelor's programs, 19 for master's programs, 16 for doctoral programs, and 9 for postdoctoral programs.

\section{RECENT GRADUATES}

Bioinformatics training programs produced 152 graduates during the period January 2002 to March 2003, according to institutions that reported graduate data. The largest number of graduates was from master's programs. Combined, the 23 institutions providing information awarded 102 master's degrees in bioinformatics. ${ }^{5}$ Only 26 doctoral degrees were awarded from 8 institutions. This is a reasonable count of the population of new Ph.D.s during this period given that of the 24 Ph.D. programs that replied to the survey 14 were too new to have awarded a degree by 2003. Nonresponding institutions could, of course, also have awarded Ph.D.s, but most of these programs were also too young to have produced graduates. Only $17 \mathrm{de}-$ grees were awarded at the bachelor's degree level as reported by the five programs that provided graduation data; four of the 10 bachelor's programs that replied to the general survey were in all likelihood too new to have awarded a degree. Only seven individuals were reported to have completed their postdoctoral appointment during this period. Overall, the number of graduates is considerably lower than would be expected from the enrollment data discussed previously. Once again, this is an indication of the newness of many of these programs. It is also a powerful reminder that in the next few years the number of

${ }^{5}$ Seven of the 23 reported zero graduates. 
TABLE I

Number of students hired from bioinformatics programs, January 2002 to March 2003

\begin{tabular}{ccccc}
\hline & Bachelor's programs & Master's programs & Doctoral programs & Postdoctoral programs \\
\hline January 2002-March 2003 & $6^{a}$ & $58^{a}$ & $11^{a}$ & $9^{b}$ \\
January 1998-March 1999 & 3 & 23 & $13^{b}$ & $14^{b}$ \\
\hline
\end{tabular}

${ }^{a}$ At least one institution indicated that students were hired during this period but could not or did not report a specific number. Therefore, the counts shown are lower bounds for the number of students hired during this period from the reporting institutions.

${ }^{b}$ Count includes student hires prior to designated start date due to survey response.

graduates is expected to increase by two or three times.

Table I shows the number of students from bioinformatics programs by level of training who were placed in positions during the period January 2002 to March 2003. Once again, not all responding institutions supplied an answer. Except for master's students, student placements in 2002-2003 changed little from the number of placements in 1998-1999. Undergraduate placements doubled but the number remained quite low, likely due to the lack of graduates from newly created bachelor's programs. Doctoral and postdoctoral placements dropped slightly, likely a result of the drop in demand in the early 2000s. On the other hand, master's placements more than doubled, rising from 23 in 1998-1999 to 58 in 2002-2003.

Private industry was the most frequent employer across levels of training, though the academic sector was a close second-particularly for students from graduate bioinformatics programs. Employment at nonprofit organizations was almost nonexistent, and government employment was limited. There was virtually no overlap in hiring institutions across levels of training, with the exception of Stanford University, which hired both masters and doctoral students.

Salary information was provided by only 13 institutions for 20 of the 84 reported placements; in 1999 salary information was provided for 35 of the 53 reported placements. At the time of the 1999 survey the small amount of salary information collected was thought to reflect the fact that many faculty simply did not know the salary offer that their students received. Moreover, at least one faculty member indicated at that time that he considered it inappropriate to make inquiries concerning starting salary. The even smaller amount of salary information collected in 2003 may reflect a continuation of that trend as well as the fact that 2003 respondents were more likely to be staff administrators with less student contact than were 1999 respondents.

Table II summarizes the frequency of reported salary ranges by level of training for the period January 2002 to March 2003. The greatest lack of salary information is at the undergraduate and doctoral levels. Only one institution provided salary data concerning placements of bachelors; only three doctoral programs reported salary data for placements; 12 master's programs supplied salary information and three postdoctoral programs supplied information.

The range of starting salaries tends to increase with the level of training as would be expected. Students with bachelor degrees from the one institution reporting salary data received a salary of $\$ 50,001-60,000$. Starting salaries for master's students from nine of the 12 reporting institutions were over $\$ 60,000$, and six of these indicated starting salaries over $\$ 125,000$ for their recently hired mas-
TABLE II

Starting salary ranges for recently hired bioinformatics students by level of training January 2002 to March 2003

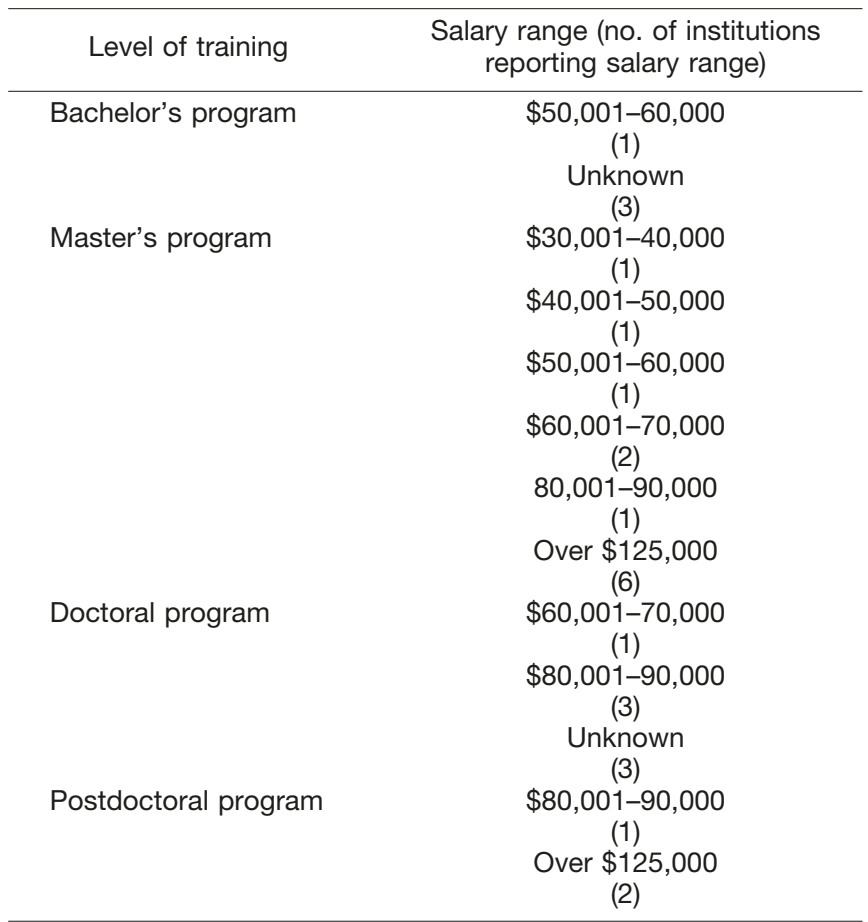

ter's students. However, starting salaries for master's students exhibit the greatest variance, ranging from a low of $\$ 30,001-40,000$ to over $\$ 125,000$. The majority of institutions providing salary information for doctoral placements reported starting salaries in the range of $\$ 80,001-90,000$, with no salaries below $\$ 60,000$. Recently hired postdoctorates received starting salaries over $\$ 80,000$, with two institutions reporting salaries of over $\$ 125,000$ for their postdoctorates. Compared with the data collected in 1999, salaries have increased most dramatically at the master's level, where the median salary went from $\$ 50,000-60,000$ to over $\$ 100,000$. Care, of course, must be taken in making these comparisons given the small amount of salary data that was made available.

\section{DEMAND IN THE BIOINFORMATICS MARKET}

To estimate demand for individuals with bioinformaticsrelated skills in the early 2000s, position announcements were analyzed. ${ }^{6}$ This provides information on the size and

\footnotetext{
${ }^{6}$ The validity of using position announcements as a measure of demand was underscored in Black and Stephan's 1999 survey of academic programs when, in response to how job positions were located for students, directors replied that the most common means was reliance on position announcements.
} 
TABLE III

Number of bioinformatics positions advertised in Science

\begin{tabular}{ccc}
\hline Year & $\begin{array}{c}\text { Number of } \\
\text { positions }\end{array}$ & $\begin{array}{c}\text { Percentage change } \\
\text { from previous period }\end{array}$ \\
\hline 1996 & 209 & - \\
1997 & 354 & 69.4 \\
2000 & 443 & 25.1 \\
2001 & 372 & -16.0 \\
2002 & 254 & -31.7 \\
\hline
\end{tabular}

origins of demand. Earlier work by Stephan and Black [2] examined bioinformatics advertisements listed in Science in 1996 and 1997. This study of recent position announcements expands this earlier data, allowing one to examine how demand has changed during the past 5 years. This time period offers insight not only into what has happened to demand as the science and technology markets of the late 1990s continued to boom but also what happened to demand during the economic downturn of 2001 and 2002.

Two indexes of bioinformatics-related positions are analyzed: position announcements listed in every issue of Science for the years 2000, 2001, and 2002 and position announcements listed on selected internet websites during the period 2002 to the beginning of 2004. Position announcements in Science were chosen because the journal consistently publishes employment announcements related to bioinformatics and provides for a comparison to Stephan and Black's 1999 analysis of bioinformatics positions. Announcements placed on internet websites were also examined to broaden the estimate of demand and explore whether trends in demand varied by method of advertisement. Two representative internet sites were chosen to monitor employment listings related to bioinformatics. ${ }^{7}$ One, www.monster.com, is a large employment board that covers all types of jobs. The other, www.bioplanet.com, is an employment information board focused solely on bioinformatics. Employment listings on www. monster.com were analyzed for the period June 2003 to January 2004 (excluding October 2003). The limited time period reflects the availability of historical ads online. Listings on www.bioplanet.com were examined for the 24month period of 2002 to 2003.

For all analyses of position announcements, a position was counted if the announcement specifically referred to bioinformatics or a closely related computational science, such as computational biology. Counts are lower bounds of actual position openings because some advertisements do not state the specific number of position openings but instead indicate more than some specified number. In such instances, the lower bound was recorded. Within each calendar year, every effort was made not to count repeated announcements for the same position.

\section{POSITIONS ANNOUNCED IN SCIENCE}

Table III shows the number of bioinformatics-related positions advertised in Science from 1996 to 2002. The number of positions announced in these ads increased

\footnotetext{
7 These websites were chosen after discussions with Steve Dahms, Steve Wickert, and participants at the symposium on Career Development for Graduate Trainees in Bioinformatics, Lake Tahoe, February 23-26, 2003.
}

from 1996 to 2000 but fell rapidly in 2001 and 2002. By 2000 , almost 450 bioinformatics positions were advertised in Science; by 2002 this number had dropped to 254 . The number of positions in 2001 closely resembled the level of positions advertised in Science in 1997, and by 2002 the number of advertised positions was fairly close to the 1996 level.

In addition to a change in the number of positions advertised during the 6-year period, the mix of institutions advertising in Science changed as well. Employment ads were dominated by industry in 1996 and 1997, with little demand coming from the academic, public, and nonprofit sectors [2]. The predominant source of demand shifted during the 2000-2002 period to the academic sector, with industrial demand considerably lower. For all degree levels combined, academic institutions grew from placing 66.8 to $79.9 \%$ of all advertised positions from 2000 to 2002 , while positions in industry fell from 21 to $16.6 \%$. Demand from the nonprofit and public sectors was minimal in comparison. The positions advertised in Science were also overwhelmingly directed at the doctoral population.

The analysis of position announcements in Science suggests that demand for individuals trained in bioinformatics peaked no later than in 2000 and has been on the decline since that time. This result holds within major sector as well as across all sectors. For example, in both academe and industry the actual number of positions advertised declined during the period at both the master's and Ph.D. level of training. The especially large decline in industrial demand, as well as demand for individuals with master's training, does, however, raise the possibility that part of the decline was a result of a change in the advertising behavior of firms seeking new employees in bioinformatics. For this reason, and also because the Science series stopped during the recession, we also analyze two sources of web-based position announcements, covering 2002 to the beginning of 2004 when the economy was well on its way to recovery.

\section{POSITIONS ANNOUNCEND ON THE INTERNET}

The analysis of online employment announcements is enlightening, in that there is virtually no overlap between online ads and those listed in Science. ${ }^{8}$ Fewer numbers of bioinformatics positions were advertised on www.bioplanet. com, with 168 openings listed in 2002 and 111 in 2003, compared with the 256 listed on www.monster.com in an 8-month period in 2003-2004. The number of positions listed on www.bioplanet.com show a decline over time in demand, which corresponds to the drop in demand suggested by declining numbers of positions in Science. Similar to employment ads in Science, the majority of internet announcements requested a doctoral degree followed by a master's degree. Unlike the distribution of demand for positions advertised in Science, recent online position announcements were largely placed by the industrial sector with relatively few ads from other sectors including academe. However, ads from www.bioplanet.com show that

\footnotetext{
${ }^{8}$ The lack of overlap suggests that this analysis does not provide an overall count of the number of vacancies in bioinformatics.
} 
industry's share of advertised openings in bioinformatics fell considerably from $82.1 \%$ in 2002 to $50.5 \%$ in 2003 , with the academic sector's share rising substantially from 9.5 to $33.3 \%$ over this same period. This suggests that the decline observed in positions in Science as well as the change in the mix of position announcements is not an artifact but characterizes the market.

Our analysis of print and online position announcements leads us to conclude that demand for individuals trained in bioinformatics declined during the 2000-2003 period, especially in industry. This may be due in part to the recession during the period of study. However, part of the decline is arguably related to the fact that the role that bioinformatics plays in drug discovery changed during the period [8]. The mix of position announcements also changed dramatically during the period. The relatively stronger demand in academe, compared with industry, in all likelihood relates to the establishment of more than 50 new degree programs in bioinformatics during the period.

\section{CONCLUSION}

The 2003 survey of academic training programs and the analysis of print and online position announcements lead to five main conclusions concerning conditions in the bioinformatics market during the period 1999-2003. First, there has been a dramatic increase in the number of academic training programs as well as the number of individuals enrolled in programs. To wit, during the period between 1999 and 2003 the number of known programs grew from 21 to 74 , and the number of students enrolled in bioinformatics programs at all degree levels grew from 169 to 881 ; the latter is a lower bound given the relatively low response rate from newer programs.

Second, the number of newly minted individuals trained in bioinformatics during the 5-year period is fairly small. For example, extrapolating from the two surveys, a ballpark estimate is that at most 78 new Ph.D.s in bioinformatics were minted during the 4-year period and 250 new master's degrees awarded in bioinformatics. ${ }^{9}$ Given the number of position announcements examined in this study, which underestimates the full level of demand, it is clear that demand exceeded the supply of newly trained individuals, especially at the Ph.D. level. In addition, there may be a mismatch between the supply of newly trained, inexperienced individuals and demand for individuals with considerable prior industrial experience [8].

Third, this analysis also suggests that the overall demand for individuals in bioinformatics, regardless of level of experience or level of training, declined over the period. The number of positions advertised in Science declined between 2000 and 2002, and the number advertised online

\footnotetext{
${ }^{9}$ Calculated using the 1999 and 2002 number of graduates and assuming that the 2000 and 2001 number of graduates is equal to the mean for the 2 years.
}

at www.bioplanet.com declined between 2002 and 2003.

Fourth, based on the extensive analysis of position announcements, the sector of demand has changed. In the mid-1990s, industry was almost exclusively the sole source of demand. By the early 2000s, demand from the academic sector had grown substantially, surpassing industry as the largest source of positions advertised in Science.

Fifth, salaries in bioinformatics have risen during the 1999-2003 period, but the substantial wage premium associated with bioinformatics jobs in the past has virtually disappeared and is unlikely to be offered under the current market conditions.

This analysis leads us to conclude that the bioinformatics labor market has gone through considerable change in recent years. In the context of a small fixed supply of specialists and rapidly expanding demand, salaries for individuals with skills in bioinformatics soared in the 1990s. Strong demand and the concern that the "seed corn was being eaten" led to the creation of numerous new training programs in bioinformatics. These training programs are now beginning to generate graduates. Many of these graduates assumed they would go to work in industry; yet positions in industry appear to be on the decline, and the positions that are available are frequently for individuals with considerable experience. The strongest area of demand in recent years has been from academe, seeking faculty to staff new programs and to broaden research expertise. Unless conditions in industry change dramatically in the next few years, it is likely that many trainees from these programs will have difficulty finding jobs in industry.

Acknowledgments-We would like to thank Eleanor Babco and Fred Fox for their help and encouragement. Asmaa El-Ganainy provided research assistance for this project. Cynthia Blasdell and Ruxue Xia assisted with the design of the web survey.

\section{REFERENCES}

[1] P. Stephan, G. Black (1999) Hiring Patterns Experienced by Students Enrolled in Bioinformatics/Computational Biology Programs, Report to the Alfred P. Sloan Foundation.

[2] P. Stephan, G. Black (1999) Bioinformatics: Does the U.S. system lead to missed opportunities in emerging fields? A case study, Science and Public Policy 26, 382-393.

[3] P. Stephan, G. Black (2000) in Capitalizing on New Needs and New Opportunities: Government Industry Partnerships in Biotechnology and Computing (C. Wessner, ed.) pp. 244-260, National Academy Press, Washington, D. C.

[4] E. Chabrow (2004) Solid money, worried minds, Information Week, April 26, 30-42.

[5] C. Henry (2001) The hottest jobs in town-Opportunities abound in bioinformatics, but qualified candidates are hard to find, Chemical and Engineering News 79, 47-55.

[6] C. Henry (2002) Careers in bioinformatics: Field is not significantly affected by economic downturn; Qualified people are still hard to find, Chemical and Engineering News 80, 47-53.

[7] P. Park (2001) Training for the bioinformatics boom, The Scientist 15, 31-32.

[8] G. Black, P. Stephan (2004) Bioinformatics: Recent Trends in Programs, Placements and Job Opportunities, Report to the Alfred P. Sloan Foundation. 